\title{
Learning Management System versus Social Networking Sites
}

\author{
Tasneem F. Alfalah ${ }^{1}$, Salsabeel F. Alfalah ${ }^{2}$, Jannat F. Falah ${ }^{3}$, Walaa Qutaishat ${ }^{4}$, Wa'ed Ishretih ${ }^{4}$, Maram \\ $\mathrm{Al}-\mathrm{Zu}^{\prime} \mathrm{bi}^{4}$ \\ ${ }^{1}$ Assistant Professor, Department of Management, Applied Science Private University, Amman, Jordan \\ ${ }^{2}$ Assistant Professor, Department of Computer Information System, the University of Jordan, Jordan \\ ${ }^{3}$ Assistant Professor, Department of Computer Information System, Al-Ahiliyya Amman University, Jordan \\ ${ }^{4}$ Department of Computer Information System, the University of Jordan, Jordan \\ Correspondence: Tasneem F. Alfalah, Assistant Professor, Department of Management, Applied Science Private \\ University, Amman, Jordan.
}

Received: April 24, 2017

doi:10.5539/ibr.v10n6p123

\author{
Accepted: May 16, 2017 \\ Online Published: May 18, 2017 \\ URL: https://doi.org/10.5539/ibr.v10n6p123
}

\begin{abstract}
Purpose - The motive of this study was the notice of the constant movement of the students in The Uni versity of Jordan (UJ) from official communities to creating groups on SNSs. The purpose of this paper is to illustrate an analysis about students' usage of E-learning and Facebook, and identifies the major functions that are missing in the e-learning system. This paper firstly, compared students' usage for Learning Management Systems (LMSs) vs. Social Networking Sites (SNSs), and secondly, investigated the students' perceptions towards educational value of integrating social networking features in the LMS through Mobile Learning (m-learning).
\end{abstract}

Design/methodology/approach - Data were collected from students from multiple sources: observation, interviews, and survey. The obtained results formed students perceptions toward currently used LMS in the university and SNSs, which lead to extracting their requirements to enhance the LMS used.

Findings - The results of this research emphasize the importance of SNSs as a communication tool and the development of e-learning systems to move beyond LMS and engage students in an active use of the system as a resource of their information and collaborative activities.

Originality/value -This study contributes to examining UJ students' perceptions toward embedding the characteristics of the smart learning and the social network services into an e-learning system. In contrast to previous studies in enhancing LMS by just integrating features of SNSs into LMS without utilizing smart learning.

Keywords: learning management systems, social networking sites, educational technology

\section{Introduction}

With the emergence of Web 2.0 whose main value is social networking, Internet users now can create and share information collaboratively and easily. Social networks provide tools that can either be presented by SNSs (such as Facebook, LinkedIn, etc.) or by indirectly extracting data about user interaction (such as emails, chats, blogs, etc.) (Aşkar, 2011; Musiał and Kazienko, 2013). These tool-initiated potentials cannot be ignored with regard to educational settings, and have moved educational technology beyond the ordinary use of computers, laptops, 3D printers, etc.

E-learning incorporates all teaching and learning activities by using networked information and communications technology. Other terms also described this mode of educational activities such as online learning, virtual learning, and web-based learning, however, e-learning embraces more than the other terms since the letter "e" which stands for "electronic" would incorporate e-learning of all educational activities, whether they were performed by individual users or groups working online or offline, through computers or other electronic devices. Moreover, a key attribute of e-learning is its ability to enable electronic access to various multimedia-based materials and flexible access to information and resources (Naidu, 2003; Pilli, 2014). E-learning has become increasingly diffused in many educational institutions implementing Learning Management Systems (LMSs). Due to their flexibility, LMSs have been used to accelerate e-learning applications whether they were used for 
distance education (off campus: who cannot be physically present in class at the time a course is being offered) or on-campus (to complement synchronous classroom learning) (Pilli, 2014).

Learning Management Systems are used to manage and deliver instructional content, and monitors the learning process by presenting the required data through tracking the progress of identifying, assessing, and meeting individual and organizational learning goals. However, many applications of LMS are limited by the form of Course Management System (CMS), and need to develop to support the evolving understanding of teaching and learning styles (Gremu and Halse, 2012). CMS which is group of software tools, typically includes a variety of online tools and environments for course communications such as: course content delivery capabilities, and an area for students to submit assignments, a grade book for scoring that can be viewed by students, assessment process such as quizzes, learning outcomes assessment, reporting of learning tasks completion, and communication tools such as discussion forums, email and announcement posts (Gremu and Halse, 2012; Naidu, 2003).

As mentioned earlier, with the inception of web 2.0 technologies, the online interaction via SNSs is increasing rapidly. There are numerous SNSs supporting a wide range of interests for millions of users by various technological affordances. Many of these users have incorporated these SNSs into their daily practices (Boyd and Ellison, 2010). A SNS is defined as "web-based services that allow individuals to (1) create a public or semi-public profile within a bounded system, (2) articulate a list of other users with whom they form relationships, (3) view their list of connections and those made by other users within the system" (Boyd and Ellison, 2010). SNSs are user-centred systems that encourage individuals to express themselves, create new relationships and maintain old ones (Yu et al., 2010). Thus, SNSs have become increasingly prevalent in all areas including the field of education (Pilli, 2014). The role of social networking sites in education varies, as new students resort to social media to gain new friends, and uni versities from the other side use social media to draw attention and encourage pupils to enrol in the uni versities. Aside from social purposes, social media is integrated in the field of education for teaching purposes as students and teachers can share files, documents, videos, and ideas (Pilli, 2014).

In contrast to SNSs, LMSs lack the personal touch and mainly support formal learning (which is institutionalized, organized, class centred, hierarchically structured educational system, and in which the learner's objective is to gain knowledge) whereas SNSs support both informal learning (which is not organized, user centred, and in terms of learning outcomes has no set objective) and non-formal learning (which lies between formal and informal learning) (Brady et al., 2010; Gremu and Halse, 2012). Researchers perceive that the diverse affordances of SNSs, developing communities of practice, student-student interaction, and online social presence among students makes online courses more often successful (Barab and Duffy, 2000).

As aforementioned, research has shown that integrating features of SNSs into a LMS enriches discussions, increases engagement, and consequently facilitates formal learning environments (Chen and Bryer, 2012). This makes the two systems complementary to each other and utilizes the benefits of each system. As a result, this will enhance both formal and informal learning.

\section{Research Background}

Considering Learning Management Systems (LMSs) as a primary educational tool in universities is expanding significantly. Simultaneously, the growth of the usage of Social Networking Sites (SNSs) among students and teaching staff means that blended learning is increasing and spreading. Many educators are considering LMSs and SNSs as a source of information and communication by mixing them or completing each other's missing parts. LMSs tend to be more focused, but lack the networking capacity, and the user centred approach that SNSs offer. On the other hand, in SNSs is difficult to keep the concentration on the topic with the communication drifts. Several studies have been done on LMSs and their insufficiency in providing social experience and failure to support personalization that is afforded by SNSs (DeSchryver et al., 2009; Naveh et al., 2010; Schroeder et al., 2010; Veletsianos and Navarrete, 2012). Further studies, some of which are discussed below, highlighted the positive impact of using social networking in education to support learners' collaboration, sharing ideas, creating products, and constructing identities (Dron and Anderson, 2009b; Greenhow, 2011; Greenhow and Robelia, 2009; Irwin et al., 2012). However, few studies investigated the integration of a LMS and a SNS (Gremu and Halse, 2012).

DeSchryver et al. (2009) investigated the impact of using the SNS Facebook for discussions in an online course. They contrasted a course using Facebook discussion boards and the other Moodle forums with regards to student conception of social presence, and their discussion interactions frequency and length. However, the evaluation results revealed that there were no differences in the measures. A similar study was done by Irwin et al. (2012) 
who investigated the students' perceptions of using 'Facebook pages' within individual university subject as a learning aid. Their preliminary evaluation suggests that Facebook has the potential to foster collaborative and cooperative learning, howe ver, this study did not examine if Facebook can enhance learning outcomes. Ractham and Fripo (2011) explored the possibility of using SNSs, specifically Facebook, to enhance learning. They found that Facebook provides usable and simple technologies for social networking to share knowledge amongst learners. Using Facebook as an informal learning environment for presenting up to date topics, moreover, the thoughts of guest experts and leaders, was successful as Cain and Policastri (2011) investigated in their study. Mozhaeva et al., 2014 verified in their study the need of an integrated approach of LMS and SN in the learning process and a need to develop LMS that enhance learning in many aspects like efficiency, frequency, information content, interaction, emotionality, motivationally and cooperatively. Further studies investigated the use of Facebook as an online discussions tool, the evaluation of students' use, and perceptions found that Facebook facilitated online discussion and is considered as a valuable study tool (DiVall and Kirwin, 2012; Estus, 2010). Although SNSs (specifically Facebook) are used sometimes by students informally for learning purposes, however, most of undergraduate students thought that Facebook was used most importantly for social reasons not for teaching purposes as revealed in a study done on undergraduate students (Madge et al., 2009). The aforementioned study explored that Facebook was a communication aid that helped students settle into university life, and it was an important social tool for informal learning to collaborate on group projects and making department level administrative arrangements but most students were opposed to the idea of contacting tutors via Facebook (Madge et al., 2009). Further studies examined the effect of Facebook on education, findings showed that faculty members more likely use traditional technologies and it is more beneficial for communication amongst students (Roblyer et al., 2010). However, some students' informal learning practices using Facebook are viewed as a source of procrastination and to avoid distraction during assessment periods students use 'SNS self-control' practices that reduce their Facebook use (Vivian, 2011).

The common things amongst all these studies are that they examined the use of LMSs and SNSs in education and their pros and cons, which showed the limitation of LMSs to support informal and non-formal learning, and the hinder of using SNSs that distracts some students, and delays the process by using more than one source to look for information. Therefore, none of the systems should disappear; both contexts should be integrated to provide a comprehensive solution (Conde et al., 2011). This can be achieved through modifying LMSs to reflect social tools that support user interactions (Gremu and Halse, 2012). To examine if social networking service enhances e-learning system, LMS (Moodle) was incorporated with Mahara (an open source portfolio system that encloses social networking features) (Shrestha and Kim, 2013). After the incorporation, Moodle has both characteristics of LMS and user management system. In this case e-learning system supports non-formal learning, and consequently enhanced collaboration between users. A similar study investigated the integration of LMS (Moodle) and a SNS (Mahara), but, the assumption proved to be incorrect and most students experienced challenges using Mahara (Gremu and Halse, 2012). This was because students were familiar with their use of SNSs like Facebook and already have well-established relationships, which affected their willingness to spend time to create connections with others in the system. Additionally, overall responses of the students indicated that Mahara's features were not useful and did not make an impact on their learning. Howe ver, they thought that social features should be part of the LMS rather than being introduced by another system, as was the case in the aforementioned study. It is noted from the above-mentioned studies that integrating features of SNSs into LMS enriches the education process and supports interaction between learners-learners or learners-instructors. Although, students are familiar with current SNSs, and there are existing open source systems that contain social networking features, however, previous studies showed that some students neither prefer using new systems that contain social networking features which they are not familiar with, nor using current SNSs in the time of assessments in order to not get distracted. Therefore, this study embedded the characteristics of the smart learning (which is learner-centred), and the social network services into the e-learning system, through using an application installed on smart phones, whereby activities can be used anytime and anywhere. As a result, this will enable students to exchange their opinions in real-time, easily adapt themselves to the system, and allow cooperative learning.

\section{Empirical Research Methodology Design}

This research investigated King Abdullah II School for Information Technology (KASIT) students in The University of Jordan (Jordan is located in the Middle East) as a case study. The study explored the students' usage for LMS vs. SNSs, and their perceptions toward tools provided in each system. Furthermore, students' insights towards social networking services in m-learning will be examined. The results will be the basis for future implementation of mobile learning application in the university. 


\subsection{Areas of Improvement}

Faculty members are encouraged to post any handouts on the Learning Management System used in the university (e-learning), on which every course being taught on each term is provided with a course site and the students enrolled into the course site are kept in sync with the e-Learning Management System.

Each student, once enrolled, is provided with a university-administered e-mail that allows authenticated e-mail communication. Moreover, each student is provided with a user-ID and password to access the e-Learning systems. Researchers recognized that some students tend to use e-learning for academic purposes (download materials, submit assignments...) and they prefer to use Facebook for communication with each other and with faculty members. This communication happens via (1) personal accounts for students and faculty members, (2) official/unofficial pages for the university and the faculties within it (3) official/unofficial groups on Facebook.

The researcher examined the use of Facebook rather than the other SNSs for the following reasons. Facebook has rapidly become the most widespread social networking site in the world (Mazman and Usluel, 2010). Although previous studies stated that students use Facebook to support both their academic and social goals (Bosch, 2009; Irwin et al., 2012; Madge et al., 2009; Mazman and Usluel, 2010; Tian et al., 2011), the majority of evidence infers that students' main drive for using Facebook is for social connectivity (Bosch, 2009; Madge et al., 2009; Mazman and Usluel, 2010; Ophus and Abbitt, 2009; Roblyer et al., 2010; Wise et al., 2011). At the commencement of our study, it was noticed that most students and employees are members of groups or 'liked' pages related to this university on Facebook, researchers believe that it is an important platform for communication. However, the use of Facebook has potential risks and limitation. Issues regarding content ownership, and students' distraction and its influence on their academic performance have been raised (Kirschner and Karpinski, 2010; Wise et al., 2011). Facebook also has an impact on dedicated study time, whilst some studies suggested that Facebook affects study time and academic results negatively, other authors have not found this association (Kabre and Brown, 2011; Kirschner and Karpinski, 2010).

Many educational institutions have used e-learning platforms to enable knowledge sharing, however, this e-learning has concentrated on close environment that may limit the sharing of open communication (Capó-Vicedo et al., 2011; Daniel et al., 2012; Othman et al., 2012). Whilst e-learning using web 2.0 technology supports interactive methods while learning (Fan et al., 2008; Othman et al., 2012). Most universities create learning social network software called "Moodle" (Othman et al., 2012). Despite the popularity of the Moodle system, which allows users to create an account, update profile, view course materials and access required information; adding functions that allow collaboration between multiple users can enhance it (Shrestha and Kim, 2013). These functions are achieved by social network services were the user could form circle of friends, control users, form a group on their own, etc. (Shrestha and Kim, 2013). Despite the fact that the Moodle system contains some social networking features, improvements is still needed to overcome the major research problem. The main focus of the research is to examine students' satisfaction of the currently used LMS and their willingness to enhance the Moodle system in the university by applying social networking features.

\subsection{Instrumentation}

To enhance the study's validity and reliability, the methodology is the result of a mixed method approach; data were collected from multiple sources as follows:

- First: Survey the number of pages and groups of the university on Facebook; An observation of the usage and discussions conducted on these pages and groups; Analysis of quantitative data: statistics of usage of Facebook pages and groups, and analysis of qualitative data: posts and discussions on Facebook;

- Second: Interviewing students to know their perceptions about e-learning and SNSs; Analysis of qualitative data obtained from interviews;

- Third: Administration of a survey to IT students: in this study, we carried out a questionnaire survey to gain knowledge about the present situation of the participants' perception on academic websites and SNSs. The survey area consists of the use of the systems, Internet, and communication tools; Analysis of quantitative and qualitative data.

\section{Results}

As abovementioned, the study started by surveying the number of pages and groups of the university on Facebook and observing their usage, then interviewing students, and finally administrating a survey to students. Shown below are the obtained results. 


\subsection{Observation}

Statistics were performed on the number of members on some of the groups and pages related to the university at the time of the conduction of this research (academic year 2016-2017). Members of these pages and groups are faculty members, administratives, students (current and graduated), and others who are interested in the university's news. As shown in Table 1, the number of people who liked official pages related to the university ranges from 2,338 to 190,192. And the number of group members in groups related to the university ranges from 1,268 to 24,656 . For the case study of this research, KASIT students usage, there was 2,338 students on the KASIT official page, and 7,376 members on "KASIT Academic Team" group whilst the current number of students 1,530 .

Table 1. Statistics of Facebook usage for UJ pages and groups

\begin{tabular}{|c|c|c|}
\hline & Page name on Facebook & Number of likes \\
\hline 1. & "University of Jordan" & 190,192 \\
\hline 2. & "University of Jordan Youth" & 180,135 \\
\hline 3. & "The University of Jordan" news & 150,380 \\
\hline 4. & "University of Jordan" website & 69,830 \\
\hline 5. & "UJ Students Union" & 42,148 \\
\hline 6. & "Students of University of Jordan" & 13,096 \\
\hline 7. & "The University of Jordan: The Faculty of Graduate Studies" & 8,727 \\
\hline 8. & "The University of Jordan events" & 6,514 \\
\hline 9. & "The University of Jordan Library" & 5,040 \\
\hline 10 . & "The University of Jordan: Faculty of Dentistry" & 5,303 \\
\hline \multirow[t]{2}{*}{11.} & "KASIT" & 2,338 \\
\hline & Group name/Link on Facebook & Members \\
\hline 1. & $\begin{array}{l}\text { University of Jordan news } \\
\mathrm{https} / / / \mathrm{ww} . \text { facebook.com/groups/univers ityofjordan/ }\end{array}$ & 24,656 \\
\hline 2. & $\begin{array}{l}\text { Official group for registration unit } \\
\mathrm{https} / / / \mathrm{www} . \text { facebook.com/groups/scireg/?ref=br_rs }\end{array}$ & 16,668 \\
\hline 3. & "Students of University of Jordan" & 12,743 \\
\hline 4. & "KASIT Academic Team” & 7,376 \\
\hline 5. & "University of Jordan" & 4,866 \\
\hline 6. & "English Conversation Club- University of Jordan" & 3,367 \\
\hline 7. & "The University of Jordan (UJ) - Department of Chemistry" & 2,132 \\
\hline 8. & "The University of Jordan: Faculty of Graduate Studies" & 1,537 \\
\hline 9. & "The University of Jordan- Computer Center" & 1,352 \\
\hline 10 . & "University of Jordan - School of Dentistry Alumni official Group" & 1,281 \\
\hline 11. & "University of Jordan, Faculty of Medicine Group" & 1,268 \\
\hline
\end{tabular}

The students perform wide range of social and academic-related tasks using Facebook such as:

- Keeping in touch with friends within the same faculty;

- Coordinating activities, as students use Facebook to create events and organize them such as trips, graduation projects ceremonies, seminars, etc.;

- Keep up to date with university news, as official pages on Facebook post updated news;

- Students from different faculties create groups to exchange information, share resources and files related to materials;

- Discuss university-related issues, and it has been noticed that decision makers were part of these discussions and took into account students opinions posted on these pages in their decision-making process;

- Communication tool between instructors and students, as many instructors created private groups for themselves to share posts related to material (documents, videos, etc.), announcements, and discussions.

\subsection{Interviews}

Interviews were conducted with students from different departments and academic years. Students were asked if they prefer to contact their instructors via SNSs. Most of the students' ans wers were "Yes, they prefer to contact their instructors via SNSs or e-mail". And for whom who answered "No" the main reason was that not all their instructors have accounts on SNSs. Students were asked if they get response on what they want, students answered that some instructors reply from their personal accounts, others from their private groups, and the rest do not reply instantly through Facebook. And finally, students were asked if e-learning satisfies all their needs or they tend to use SNSs for some services, most of the answers were that students prefer to use SNSs when they need to contact instructors quickly, as it is easier contact them through SNSs via mobile applications. 


\subsection{Questionnaire}

The questionnaire design and analysis was as follows; the questionnaire is divided into four parts consisted of 22 questions:

- The first part includes 4 questions regard the demographic information (personal profile of the student);

- The second part that contains 2 questions about the students' usage of Internet and SNSs;

- The third part that contains 4 closed-ended questions. This part concerns the use of the e-learning system by students and how satisfied they are compared with SNSs;

- The fourth part includes another 5 closed-ended questions concern statistics about usage SNSs;

- And the fifth part has 4 closed-ended and 3 open-ended questions to compare between usage of e-learning and SNSs. Students were given in this part enough space to express their opinions about features that they would like to see in e-learning, and pros and cons of SNSs and e-learning.

Analyses of the data that was collected via questionnaire administered online, KASIT consisted of 1530 students at the time that the research was commenced. A questionnaire was administered to 261 students (participants volunteered to participate in the research): The analysis of the demographics of the questionnaire leads us to the following results (Question 1-Question 4):

The dominant age of the students was between 20 and 22 years with a percentage of $81.2 \%$. The parameter is confirmed since the participants who consist the $75.2 \%$, study in academic years 3 and 4 with percentages of $29.89 \%$, and $46.73 \%$ respectively. From the whole sample of this research, $32.2 \%$ of the participants were males and the rest $67.8 \%$ are females. The vast percentage of the participants, $39.6 \%$ were in The Computer Information Systems Department, while $32.7 \%$ and $27.7 \%$ were in Business Information Systems and Computer Science Departments respectively.

The analysis of the second part of the questionnaire about the students' usage of Internet and SNSs was as follows (Questions 5 and 6):

Participants were asked closed questions about the time spent on Internet. It is obvious from answers on question 5 that students spend a significant amount of time online. The majority of participants, $32.94 \%$, spend between 3 and 6 hours on internet on daily basis, followed by $28.83 \%$ and $28.35 \%$ spend more than 6 hours and between 1 and 3 hours on Internet on daily basis respectively, then $8.44 \%$ spend between 30 minutes and 1 Hour, and only $1.92 \%$ spend less than 30 minutes on internet on daily basis.

In the sixth question, students were asked about the most used SNS by them. The majority of students, $63.3 \%$, use Facebook the most, then $18.81 \%$ use Whatsapp the most, then $10.93 \%$ use YouTube the most, $2.9 \%$ use Twitter the most, and $4.07 \%$ stated that they use other SNSs.

The analysis of the third part of the questionnaire (Question 7 - Question 10) concerns the use of the e-learning system by students and how satisfied they are compared with SNSs was as follows:

From the whole of the sample that participated in this research, the answer on the question about using academic websites (e-learning, faculties websites, faculties members personal websites) to get academic materials and other related documents (where students can select multiple options), leads us to the conclusion that the percentage of the students who prefer to use academic websites to get academic materials and documents is large, as shown in Figure 1, at a total of $89.1 \%$ use e-learning. Whereas $19.8 \%$ of the participant KASIT website, $14.9 \%$ use Faculty members webpages, and $5.9 \%$ use other resources.

The answers on the question about the usage of e-learning to download materials and academic-related work was: the majority of $34.82 \%$ use e-learning once a week, $18.39 \%$ of the participants use e-learning once a month, whilst $18.07 \%$ use e-learning on daily basis, then $8.03 \%$ use e-learning once in the semester, and the rest of $7.67 \%$ use e-learning irregularly. 


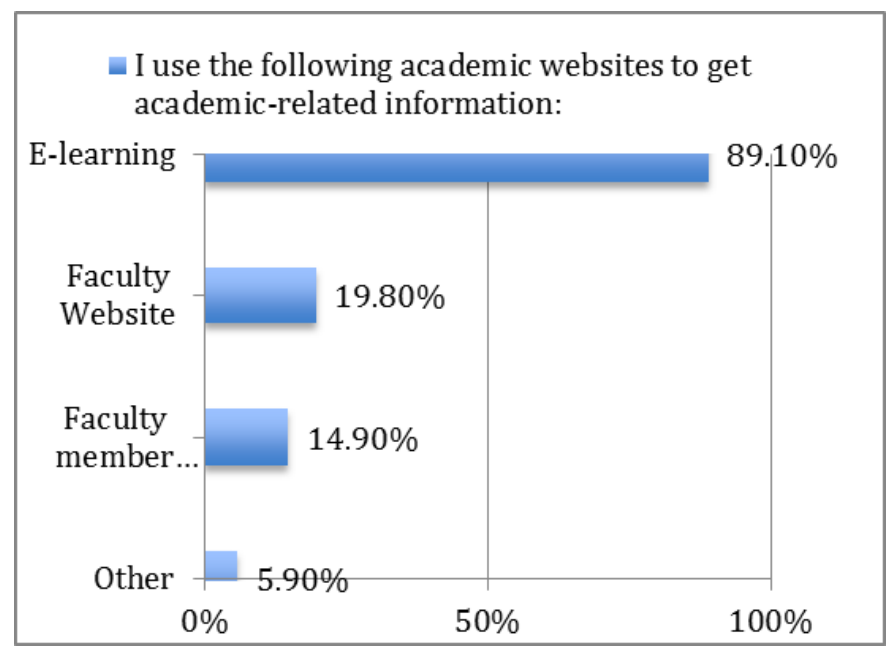

Figure 1. Results of question 7 "I use the following academic websites to get academic-related information

The results of question 9 "I trust e-learning as a source of materials more than SNSs (such as Facebook groups)" (which adopts the five-rated Likert type (1. Strongly Disagree -5 . Strongly Agree) indicates that students trust e-learning as a source to get materials as 67.7\% (37.8\% and 29.9\% answered "Strongly Agree" and "Agree" respectively), 3.7\% answered "Neutral", and the rest of $28.8 \%$ (14.9\% and $13.9 \%$ answered "Strongly Disagree" and "Disagree" respectively) prefer to use SNSs more than e-learning as a source for materials.

Participants were asked in question 10 about their satisfaction with the options that e-learning provides for communication and academic tasks (such as downloading materials, submitting assignments, and conducting online quizzes, etc.), most of the participants with the percentages of $36.46 \%$ and $14.22 \%$ were "Dissatisfied" and very "Dissatisfied" respectively, as only $8.03 \%$ of participants were "Very Satisfied", and $27.98 \%$ were "Satisfied" and the rest of $13.3 \%$ were "Neutral". Students prefer to have the notifications aspect in academic websites to enhance and accelerate communication process between students and instructors, as the majority of $65 \%$ responded.

The analysis of the fourth part of the questionnaire concern statistics about usage SNSs was as follows (Question11 - Question15):

Participants were asked in question 11 how frequently do they access SNSs to accomplish academic task, 24.14\% answered "Very Frequently", 43.31\% answered "Frequently", 19.52\% answered "Occasionally", 9.2\% answered "Rarely", 3.07\% answered "Very Rarely", and the rest of $0.7 \%$ answered "Never".

The result of question 12 shown in Figure 2, which asked the participants about their usage of the mentioned SNSs for communicating colleagues and instructors, as well as for academic-related tasks.

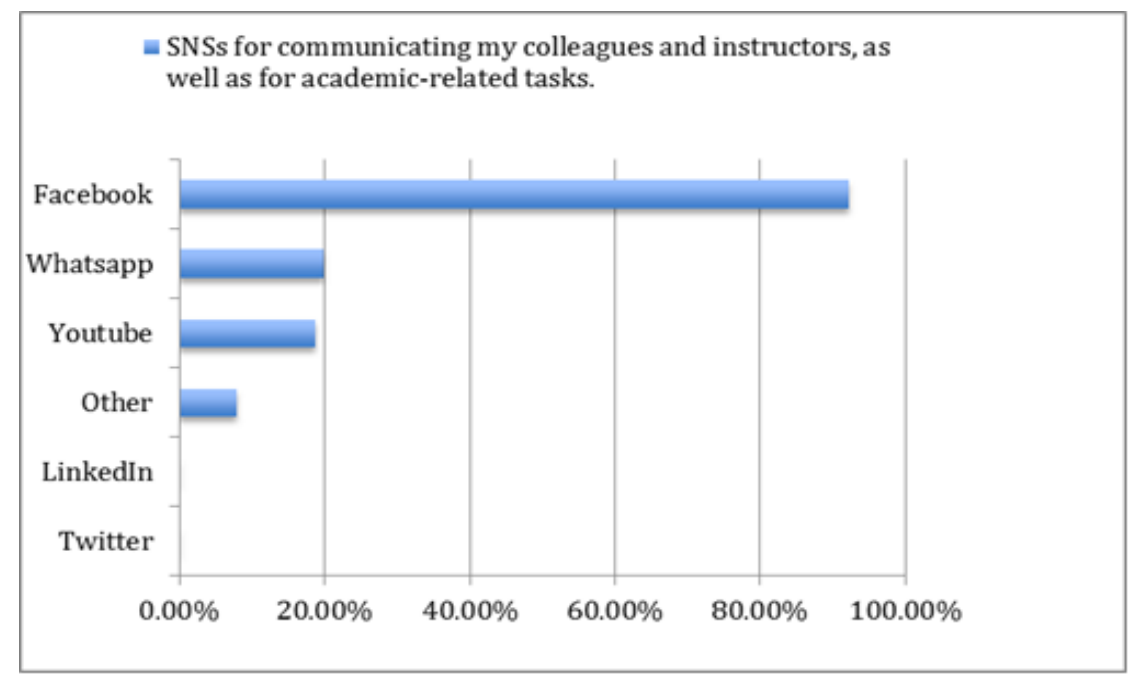

Figure 2. Results of question 12 "I use the following SNSs for communicating my colleagues and instructors, as well as for academic-related tasks." 
The result of question 13 shown in Figure 3, which asked the participants about their reasons of using SNSs for communicating instructors. $63.4 \%$ of students use SNSs for contacting their instructors because they "get faster responses", $32.7 \%$ and $25.7 \%$ use SNSs for communicating instructors because "Accessibility (via smartphones) is easier than e-learning" and "Less steps required" respectively, $14.9 \%$ do not contact their instructors via SNSs.

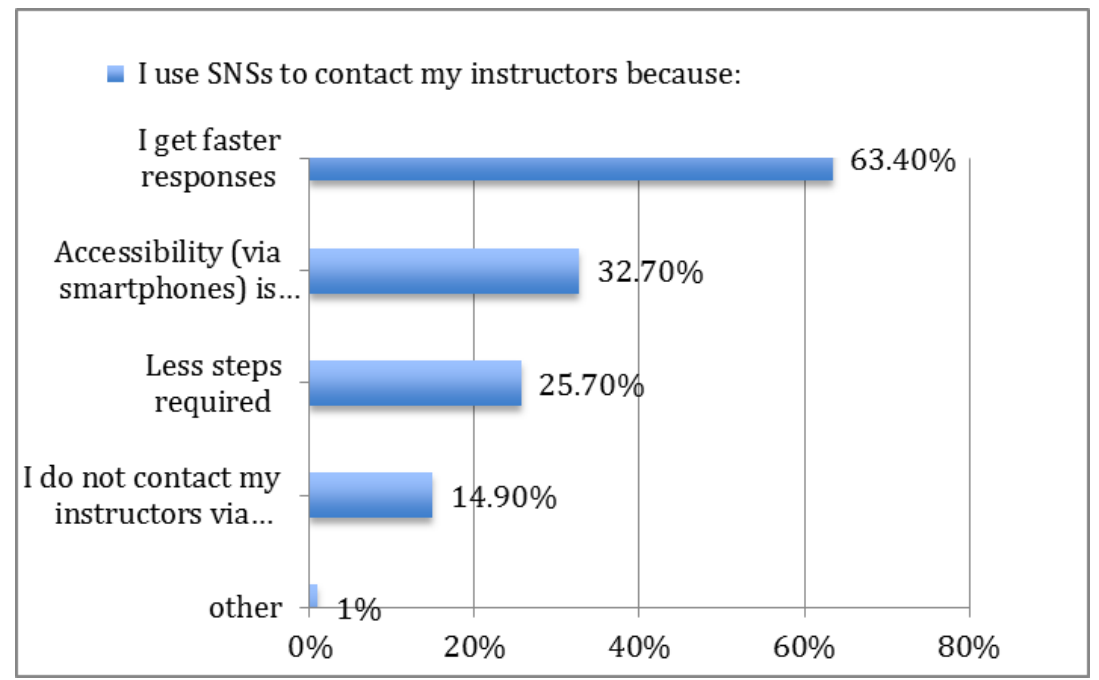

Figure 3. Results of question 13 "I use SNSs to contact my supervisors because:"

The result of question 14 shown in Figure 4, which asked the participants about their reasons of using SNSs for communicating their colleagues. 50.5\% of the students use SNSs for contacting their colleagues because they get the latest news related to their faculty quickly, $42.6 \%$ and $38.6 \%$ use SNSs for communicating colleagues because they get faster notifications and "It improves our communication" respectively, then $25.7 \%$ use SNSs for communicating colleagues because "Accessibility (via smartphones) is easier than e-learning", $6.9 \%$ do not contact their colleagues via SNSs.

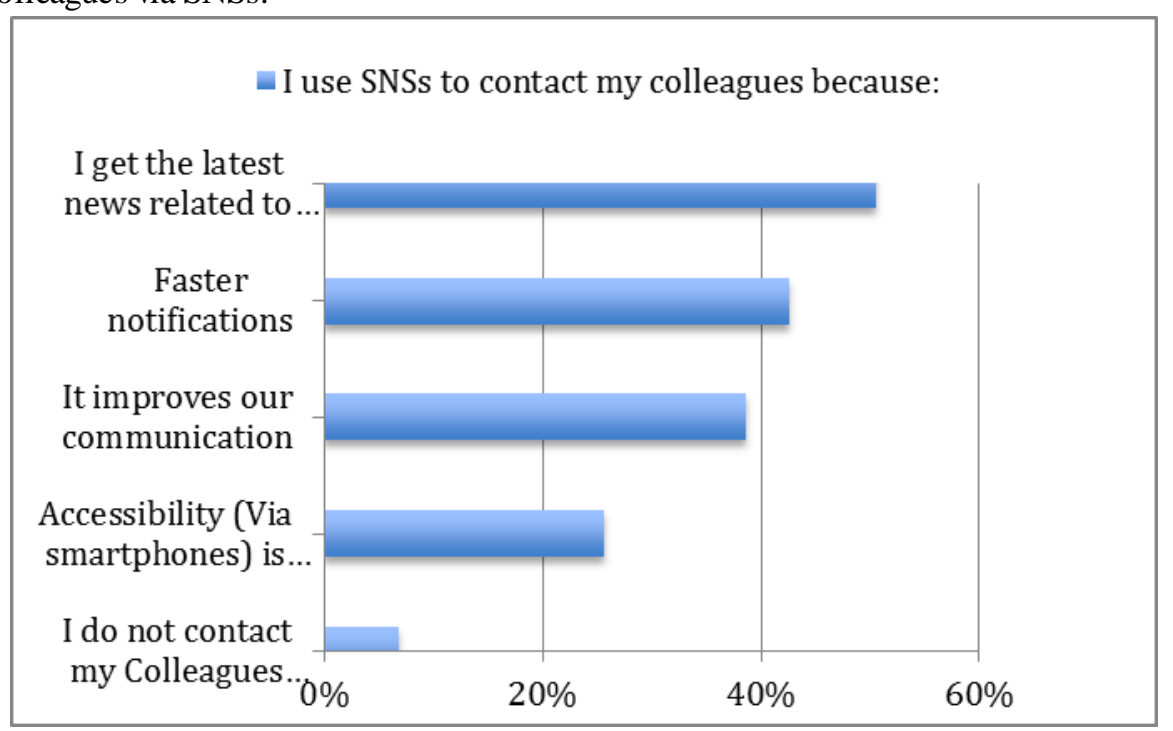

Figure 4. Results of question 14 "I use SNSs to contact my colleagues because:"

It is noticed that participants get distracted and spend extra time when they use SNSs to accomplish any academic task as the results of question 15 showed (Figure 5). As $50.17 \%$ of participants spend extra time on unrelated information when they use SNSs to get academic-related information. Whereas, $26.81 \%$ answered "Maybe" and $22.98 \%$ of the students do not spend extra time on unrelated information when they use SNSs to get academic-related information. 


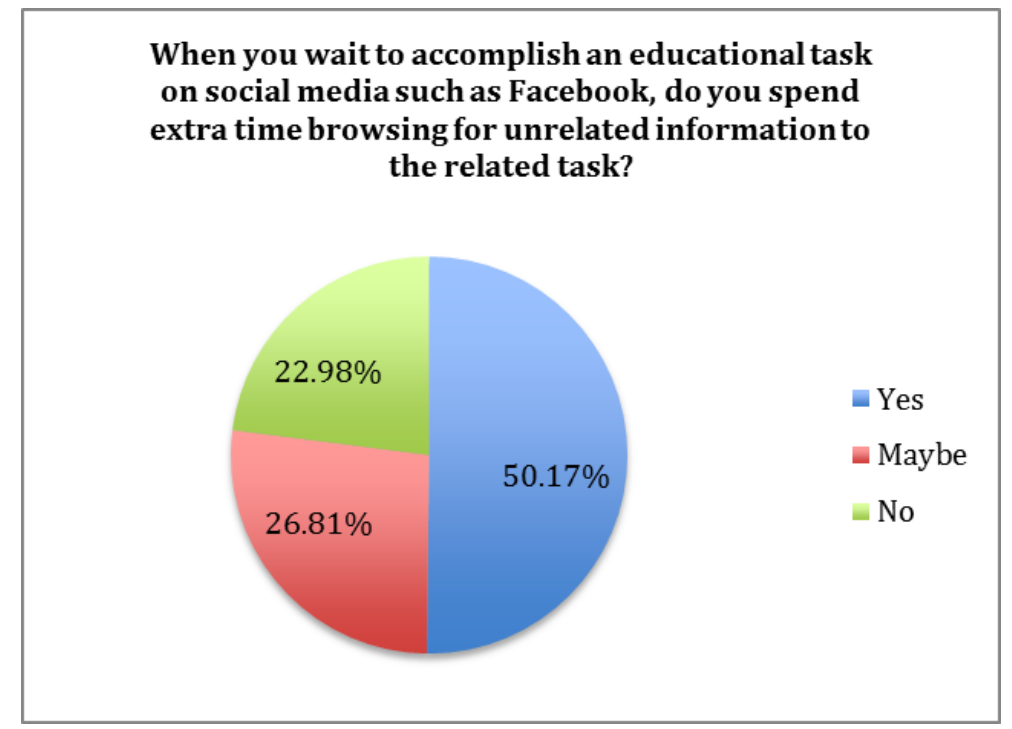

Figure 5. Results of question 15 "When you wait to accomplish an educational task on social media such as Facebook, do you spend extra time browsing for unrelated information to the related task?"

The analysis of the fifth part of the questionnaire to compare between usage of e-learning and SNSs (Question 16 - Question 22) was as follows:

The researcher can notice that students prefer to get materials from e-learning and they express interest in SNSs for communication. As results of Questions 16 and 17 showed (Figures 6 and 7 and respectively ). 79.2\% of students prefer to download materials from e-learning, 16.8\% prefer to get materials from SNSs, and the rest of 4\% answered "Other" (which includes hardcopy materials from colleagues, bookshops, etc.). In Question 17 participants were asked if they prefer to contact their instructors via SNSs, academic websites, or other. As shown in Figure the vast majority of the students, $61.88 \%$, prefer to contact their instructors via SNSs, whereas $21.6 \%$ of the participants prefer to contact their instructors via academic websites and $17 \%$ ans wered "Other" (As face-to-face communication in office hours).

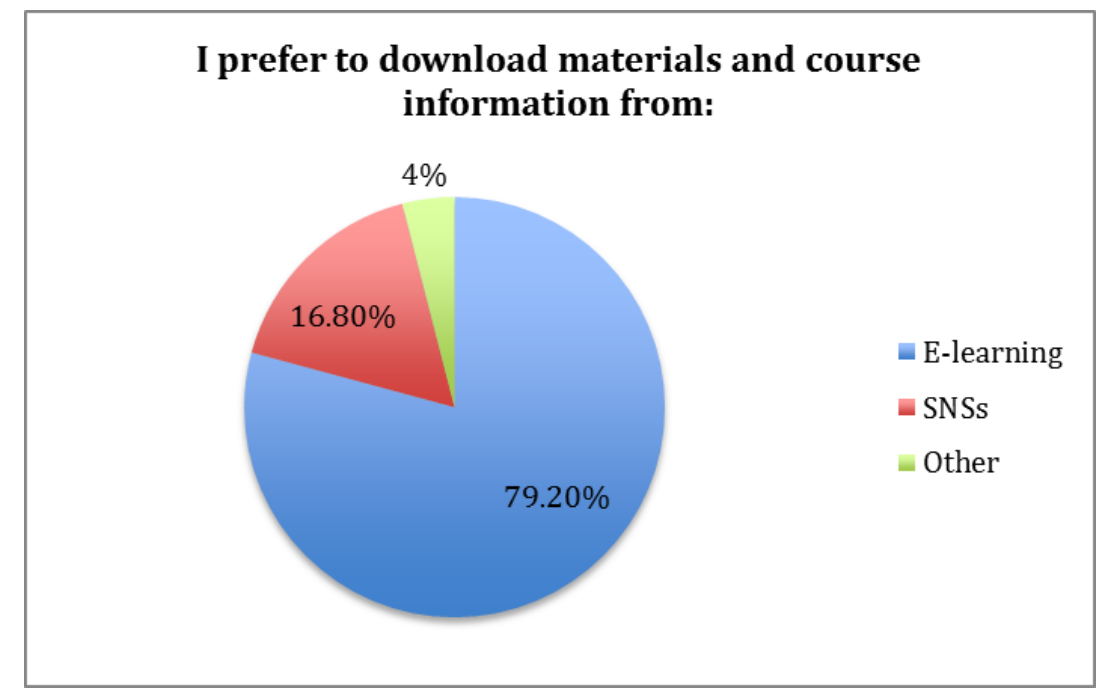

Figure 6. Results of question 16 "I prefer to download materials and course information from:" 


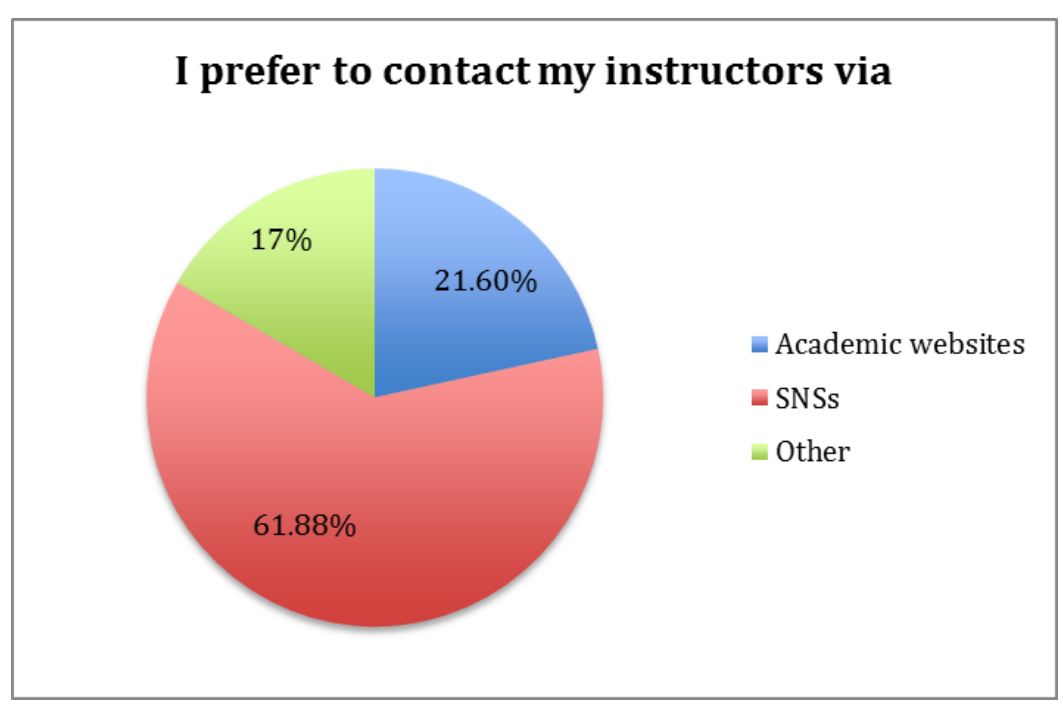

Figure 7. Results of question 17 "I prefer to contact my instructors via:"

Questions 18 was "If e-learning become m-learning (mobile based application) I will use it more frequently" and most of the participants responded positively with the percentages of $39.07 \%$ and $29.13 \%$ "Strongly Agree" and "Agree" respectively, 13.03\% were "Undecided", and 8.41\% and 10.34\% "Disagree" and "Strongly Disagree" respectively.

Participants were not satisfied with the communication tools provided in e-learning, thus they still prefer to use SNSs even if communication tools were fostered in e-learning as $48.67 \%$ of the participants responded, whereas, $25.69 \%$ were uncertain and the rest of $25.69 \%$ prefer to use e-learning if communication tools were enhanced (Question 19). However, it has been noticed that participants did not prefer to use e-learning even if communication tools were enhanced because they prefer to use mobile applications to websites. This outcome was affirmed by Question 18 results which showed that $68.2 \%$ of participants prefer to use e-learning if it was via mobile application (details are shown in Question 18).

The open-ended question (Question 20) was about the things that students would like to see in the academic websites to enhance communication and/or perform academic tasks on e-learning easier (such as downloading materials, uploading assignments, etc.).

From the population who answered this question, we can summarize the answers as follows:

- In order to ease access and get the required information in timely manner, most students prefer to access the system via mobile application (m-learning).

- Students also focused on enhancing the communication features; real-time interaction, notifications, interactive students groups, reminders and alerts for deadlines.

- Reduce the number of steps required to login and download materials.

- Add all required information in the system so they will not need to get information from multiple sources (i.e. university or faculty website, Facebook, etc.). And students would like to find all the related announcements to the materials regarding exams, events, assignments, and deadlines on e-learning.

- More user friendly Graphical User Interface (GUI).

In the second open-ended question (Question 21) students were asked to write down advantages and disadvantages of SNSs if they find any. And their answers were summarized as follows:

- SNSs advantages: Students are accessing Facebook, Twitter, LinkedIn and other such SNSs to connect and share information with those around them; since most people are continuously connected to the Internet through their mobiles, tablets, etc. it is easier to share information with all connections (friends, family, etc.); Immediacy: easier and faster to interact with peers or instructors about class-related topics. Likewise, Facebook group's posts are fast to write and read; new students get the additional benefit of gaining new friends and to participating in special interest group communities; students can find experts in their fields and contact them easily.

- When students were asked about social media disadvantages their answers were as follows: 
- Students are being distracted when they do their study due to the difficulty of keeping concentration on topic with the increase in communication drifts.

- Students find SNSs unreliable source for academic materials.

- Posted messages in informal groups sometimes are not consistent, and topics organization is not always clear.

In the third open-ended question (Question 22) students were asked to write down advantages and disadvantages of e-learning if they find any. And their answers were summarized as follows:

- e-learning advantages:

- Centralized learning environment: since the main function e-learning is delivering lesson content to students, students mainly concentrate only on the substance of the lesson topic.

- Easier to access academic materials.

- Trusted content regarding announcements, assignments, grades, and incorporated lessons into the standardized curriculum.

- Regard disadvantages of e-learning students were asked to mention them if they find any, and the main issues for students were the lack of:

- Communication tools;

- $\quad$ Instant feedback;

- Notifications, alerts, and reminders.

\section{Discussion}

The results of analysis underlines students perceptions and usage of LMS and SNSs: all students generally appreciate them; particularly the survey confirmed the active involvement of students on SNSs for communication with instructors (61.88\% of participants) and their positive acceptation of LMSs as an important source to get materials and lessons notes (79.2\% of participants). Despite the appreciation just described, LMSs are losing population in favor of communities created on Facebook. Students declared that it is more practical (accessed anywhere anytime via smart phones) and immediate. On the other hand, students trust LMSs more as a source of information and academic documents, and they see that LMSs are more focused and do not distract them to accomplish required tasks in timely manner. The qualitative data gathered from the open questions of surveys is consistent with this result as $92.1 \%$ of students contact their instructors via Facebook and $72.3 \%$ of them use Facebook the most amongst all other SNSs whereas only $21.6 \%$ of students use academic websites for communication.

Although previous research suggested that Facebook has potential benefits as an academic tool (Mason, 2006; Selwyn, 2007), however, in our research it is clear that Facebook was an important social tool used by the majority of the respondents as a communication aid. Students generally thought that Facebook utilization for social purposes, informal learning purposes (interactions about academic-related matters), but not for formal learning purposes (which involves formal assessment).

Despite the fact that students prefer to use Facebook for communication, students concern is the credibility of the shared content and the distraction, as $50.17 \%$ of participants spend extra time on irrele vant information when they use SNSs to get academic-related information. Here students appeared to draw a distinction between the positive use of Facebook for communication and the negative effect on time and reliability of shared academic-related materials. On the other hand students are not satisfied with the e-learning's communication tools as $50.68 \%$ of participants stated. Notably, their suggestions were to add communication functions such as notifications, reminders, and alerts as the majority responded as the analysis of the qualitative data in open-ended questions revealed. But they still prefer to use SNSs even if communication tools were enhanced as $48.67 \%$ of the participants responded unless it becomes mobile based application. This result was reinforced by the participants' responses of the majority of $68.2 \%$ who prefer to use e-learning if it was via mobile application.

Findings from this study reinforce the results of recent studies (Kirschner, 2001; Cheong et al., 2012; McLoughlin and Luca, 2000) on the importance of enhancing LMSs, demonstrating the educational value of smart learning system which plays crucial role in complementing cooperative function, this was considered as a limitation in the current e-learning system. Using smart phones facilitates collaborative learning through the interaction between learner-learner and learner-instructor. Collaborative learning (which is the shift from traditional teacher-centered approaches to new learning approaches including student-centered, social and active 
learning (Kirschner, 2001)) allows learners achieve an academic goal collectively. This in its turn enhances learners' critical thinking and problem solving abilities, and retains information longer compared to individual learning (Kirschner, 2001; Cheong et al., 2012; McLoughlin and Luca, 2000).

Therefore, this paper presents the readiness and perceptions of students to the transition from e-learning to $\mathrm{m}$-learning with the characteristics of smart learning by implementing social networking services.

\section{Conclusion}

This paper discusses the integration of social media tools in education while comparing these tools with the ones provided by LMSs. Actually, this paper presents both aspects of these tools. A clear picture emerged that Facebook is an important social tool used by the majority of the respondents as a communication aid but not for formal teaching purposes. Though most of students are keen to contact instructors on Facebook but they spend more time on unrelated information, which takes away from the time determined for studying. Since LMSs primarily just delivers lesson content, students are mainly concentrating on the lesson topic. Students would prefer to use e-learning if communication tools were enhanced and it became mobile based.

\section{Future work}

In this study, we went through the theoretical part of examining students' perception towards LMSs, SNSs, and willingness to adapt m-learning system to fulfill students' requirements. We therefore will do further theoretical research on the university's instructors to examine the same aspects. After the analysis, major missing functions in the Moodle system will be identified. The main concern of the practical part is to implement a mobile-based learning system for the purpose to take the researches' findings further, whereby smart learning system will enhance students' performance.

The expected outcomes from the practical part are: First, m-learning will afford social networking features, and students will interchange information real-time, as a result, interaction between learner-learner and learner-instructor will be easier. Furthermore, immediate feedback will facilitate solving problems, and utilize group-learning advantages, which will enable cooperative learning. Second, m-learning system will use social networking features that students are familiar with. Accordingly, students will easily adopt the system. This will support their interest in learning and enhance their academic performance. Third, by integrating the social networking features in the university system, the content ownership of the exchanged materials, discussions, and any other information will be for the university. Moreover, all the above-shared information will be, to some extent, related only to university issues, which will diminish students' distraction and keep them focused.

\section{References}

Aşkar, P. (2011). Social network analysis for e-learning environments. Procedia-Social and Behavioral Sciences, 28, 992. https://doi.org/10.1016/j.sbspro.2011.11.183

Barab, S. A., \& Duffy, T. (2000). From practice fields to communities of practice. Theoretical foundations of learning environments, 1(1), 25-56. https://doi.org/10.1017/cbo9780511805080.010

Bosch, T. E. (2009). Using online social networking for teaching and learning: Facebook use at the University of Cape Town. Communicatio: South African Journal for Communication Theory and Research, 35(2), 185-200. https://doi.org/10.1080/02500160903250648

Boyd, D., \& Ellison, N. (2010). Social network sites: definition, history, and scholarship. IEEE Engineering Management Review, 3(38), 16-31. https://doi.org/10.1109/EMR.2010.5559139

Brady, K. P., Holcomb, L. B., \& Smith, B. V. (2010). The use of alternative social networking sites in higher educational settings: A case study of the e-learning benefits of Ning in education. Journal of Interactive Online Learning, 9(2), 151-170. https://doi.org/10.1007/978-90-481-9151-2_23

Cain, J., \& Policastri, A. (2011). Using Facebook as an informal learning environment. American journal of pharmaceutical education, 75(10), 207. https://doi.org/10.5688/ajpe7510207

Capó-Vicedo, J., Mula, J., \& Capó, J. (2011). A social network-based organizational model for improving knowledge management in supply chains. Supply Chain Management: An International Journal, 16(4), 284-293. https://doi.org/10.1108/13598541111139099

Chen, B., \& Bryer, T. (2012). Investigating instructional strategies for using social media in formal and informal learning. The International Review of Research in Open and Distributed Learning, 13(1), 87-104. https://doi.org/10.19173/irrodl.v13i1.1027

Cheong, C., Bruno, V., \& Cheong, F. (2012). Designing a mobile-app-based collaborative learning system. 
Journal of Information Technology Education, 11, 97-119. https://doi.org/10.1109/icl.2015.7318027

Conde, M. A., García, F. J., Alier, M., \& Casany, M. J. (2011). Merging learning management systems and personal learning environments. In PLE Conference 2011 . https://doi.org/10.1109/dexa.2010.36

Daniel, J. (2012). Being at the Leading Edge: How to Give the Quest for Excellence a New Meaning: Elearning: Open or Closed? International Journal of Excellence in Education, 4(3), 1-12. https://doi.org/10.1190/tle351200s1.1

DeSchryver, M., Mishra, P., Koehleer, M., \& Francis, A. (2009). Moodle vs. Facebook: Does using Facebook for discussions in an online course enhance perceived social presence and student interaction? In I. Gibson et al (Eds.), Proceedings of Society for Information Technology \& Teacher Education International Conference (pp.329-336). Chesapeake, VA: AACE. https://doi.org/10.1109/hicss.2011.479

DiVall, M. V., \& Kirwin, J. L. (2012). Using Facebook to facilitate course-related discussion between students and faculty members. American journal of pharmaceutical education, 76(2), 32. https://doi.org/10.5688/ajpe76232

Dron, J., \& Anderson, T. (2009b). Lost in social space: Information retrieval issues in Web 1.5. Journal of Digital Information, 10(2), 1-12. https://doi.org/10.1002/9781119004943.oth2

Estus, E. L. (2010). Using Facebook within a geriatric pharmacotherapy course", American journal of pharmaceutical education, 74(8), 145. https://doi.org/10.5688/aj7408145

Fan, X., Wang, Z., \& Liao, L. (2008). Web 2.0 Environment's Support to the Web Learning Community", In Knowledge Acquisition and Modeling, 2008. KAM'08, International Symposium on (pp. 530-533), IEEE. https://doi.org/10.1109/kam.2008.176

Greenhow, C. (2011). Online social networking and learning. International Journal of Cyber Behavior, Psychology and Learning, 1(1), 36-50. https://doi.org/10.4018/ijcbpl.2011010104

Greenhow, C., \& Robelia, B. (2009). Old communication, new literacies: Social network sites as social learning resources. Journal of Computer-mediated Communication, 14(4), 1130-1161. https://doi.org/10.1111/j.1083-6101.2009.01484.x

Gremu, C., \& Halse, M. (2012). The Educational Value of Integrating a Social Networking Platform and a Learning Management System. South Africa: Rhodes University, available at: http://www.cs.ru.ac.za/research/g12G1792/documents/shortpaper.pdf (Accessed at 4 November 2016).

Irwin, C., Ball, L., Desbrow, B., \& Leveritt, M. (2012). Students' perceptions of using Facebook as an interactive learning resource at university. Australasian Journal of Educational Technology, 28(7), 1221-1232. https://doi.org/10.14742/ajet.798

Kabre, F., \& Brown, U. J. (2011). The influence of Facebook usage on the academic performance and the quality of life of college students. Journal of Media \& Communication Studies, 3(4), 144-150.

Kirschner, P. A., \& Karpinski, A. C. (2010). Facebook and academic performance. Computers in Human Behavior, 26(6), 1237-1245. https://doi.org/10.1016/j.chb.2010.03.024

Kirschner, P. A. (2001). Using integrated electronic environments for collaborative teaching/learning. Learning and Instruction, 10, 1-9. https://doi.org/10.1016/S0959-4752(00)00021-9

Madge, C., Meek, J., Wellens, J., \& Hooley, T. (2009). Facebook, social integration and informal learning at university: 'It is more for socializing and talking to friends about work than for actually doing work'. Learning, Media and Technology, 34(2), 141-155. https://doi.org/10.1080/17439880902923606

Mason, R. (2006). Learning technologies for adult continuing education. Studies in Continuing Education, 28(2), 121-133. https://doi.org/10.1080/01580370600751039

Mazman, S. G., \& Usluel, Y. K. (2010). Modeling educational usage of Facebook. Computers and Education, 55(2), 444-453. https://doi.org/10.1016/j.compedu.2010.02.008

McLoughlin, C., \& Luca, J. (2000). Cognitive engagement and higher order thinking through computer conferencing: We know why but do we know how. In Flexible futures in tertiary teaching. Proceedings of the 9th Annual Teaching Learning Forum, 2-4, Perth, Australia: Curtin University of Technology.

Mozhaeva, G., Feshchenko, A., \& Kulikov, I. (2014). E-learning in the Evaluation of Students and Teachers: LMS or Social Networks? Procedia-Social and Behavioral Sciences, 152, 127-130. https://doi.org/10.1016/j.sbspro.2014.09.168 
Musiał, K., \& Kazienko, P. (2013). Social networks on the Internet. World Wide Web, 16(1), 31-72. https://doi.org/10.1007/s11280-011-0155-z

Naidu, S. (2003). E-learning: A guidebook of principles, procedures and practices. Commonwealth Educational Media Centre for Asia (CEMCA), New Delhi, pp. 1, 4-6.

Naveh, G., Tubin, D., \& Pliskin, N. (2010). Student LMS use and satisfaction in academic institutions: The organizational perspective. The Internet and Higher Education, 13(3), 127-133. https://doi.org/10.1016/j.iheduc.2010.02.004

Ophus, J. D., \& Abbitt, J. T. (2009). Exploring the potential perceptions of social networking systems in university courses. MERLOT Journal of Online Learning and Teaching, 5(4), 639-648.

Othman, M. S., Suhaimi, S. M., Yusuf, L. M., Yusof, N., \& Mohamad, N. (2012). An analysis of social network categories: social learning and social friendship. Procedia-Social and Behavioral Sciences, 56, 441-447. https://doi.org/10.1016/j.sbspro.2012.09.674

Pilli, O. (2014). LMS Vs. SNS: Can Social Networking Sites Act as a Learning Management Systems. American International Journal of Contemporary Research, 4(5), 90-97.

Ractham, P., \& Firpo, D. (2011). Using social networking technology to enhance learning in higher education: A case study using Facebook. In System Sciences (HICSS), 2011 44th Hawaii International Conference on (pp. 1-10), IEEE. https://doi.org/10.1109/HICSS.2011.479

Roblyer, M. D., McDaniel, M., Webb, M., Herman, J., \& Witty, J. V. (2010). Findings on Facebook in higher education: Acomparison of college faculty and student uses and perceptions of social networking sites. The Internet and higher education, 13(3), 134-140. https://doi.org/10.1016/j. iheduc.2010.03.002

Schroeder, A., Minocha, S., \& Schneider, C. (2010). The strengths, weaknesses, opportunities and threats of using social software in higher and further education teaching and learning. Journal of Computer Assisted Learning, 26(3), 159-174. https://doi.org/10.1111/j.1365-2729.2010.00347.x

Selwyn, N. (2007). Screw blackboard... do it on Facebook!: An investigation of students' educational use of Facebook. Paper presented to the Pole 1.0 - Facebook social research symposium, November 15, at University of London, available at: http://www.scribd.com/doc/513958/Facebook-seminar-paper-Selwyn (accessed at November 5, 2016).

Shrestha, S., \& Kim, J. M. (2013). Bridging the Gap between E-Learning and Knowledge Management (KM): An enhancement of Moodle system by applying KM Functions. Internat J SciTechnol, 2(1), 104-111.

Tian, S. W., Yu, A. Y., Vogel, D., \& Kwok, R. C. W. (2011). The impact of online social networking on learning: a social integration perspective. International Journal of Networking and Virtual Organisations, 8(3-4), 264-280. https://doi.org/10.1504/IJNVO.2011.039999

Veletsianos, G., \& Navarrete, C. (2012). Online social networks as formal learning environments: Learner experiences and activities. The International Review of Research in Open and Distributed Learning, 13(1), 144-166. https://doi.org/10.19173/irrodl.v13i1.1078

Vivian, R. (2011). University students' informal learning practices using Facebook: help or hindrance? In International Conference on ICT in Teaching and Learning, 254-267, Springer Berlin Heidelberg.

Werquin, P. (2010). Recognition of non-formal and informal learning: Country practices. Organisation de coopération et de développementéconomiques OCDE, ParisDisonible en, available at: http://www.connect.tsoft.hu/digitalcity/servlet/PublishedFileServlet/AAABEWBX/OECD-Report.pdf (accessed at 4 September 2016)

Wise, L. Z., Skues, J., \& Williams, B. (2011). Facebook in higher education promotes social but not academic engagement. Changing demands, changing directions. Proceedings ascilite Hobart, 1332-1342.

Yu, A. Y., Tian, S. W., Vogel, D., \& Kwok, R. C. (2010). Can learning be virtually boosted? An investigation of online social networking impacts. Computers \& Education, 55, 1494-1503. https://doi.org/10.1016/j.compedu.2010.06.015

\section{Copyrights}

Copyright for this article is retained by the author(s), with first publication rights granted to the journal.

This is an open-access article distributed under the terms and conditions of the Creative Commons Attribution license (http://creativecommons.org/licenses/by/4.0/). 